\title{
Pain assessment following endodontic treatment using two automated systems compared to manual treatment in primary molars
}

\author{
Ibrahim Alnassar ${ }^{1, A-F}$, Mohamed Altinawi ${ }^{1, A-F}$, Mohammad Salem Rekab ${ }^{2, A-F}$, Imad Katbeh ${ }^{3, A, C-F}$, Alexander Khasan ${ }^{4, C, D, F}$, \\ Hayan Almokaddam ${ }^{3, B, D, F}$ \\ ${ }^{1}$ Department of Pediatric Dentistry, Faculty of Dentistry, Damascus University, Syria \\ ${ }^{2}$ Department of Endodontics, Faculty of Dentistry, Damascus University, Syria \\ ${ }^{3}$ Department of Pediatric Dentistry and Orthodontics, Peoples' Friendship University of Russia (RUDN University), Moscow, Russia \\ ${ }^{4}$ Department of Prosthodontics, Peoples' Friendship University of Russia (RUDN University), Moscow, Russia \\ A - research concept and design; $B$ - collection and/or assembly of data; $C$ - data analysis and interpretation; \\ $D$ - writing the article; $E$ - critical revision of the article; $F$ - final approval of the article
}

Address for correspondence

Imad Katbeh

E-mail: katbekh-i@rudn.ru

\section{Funding sources}

None declared

Conflict of interest

None declared

Received on September 7, 2020

Reviewed on October 4, 2020

Accepted on November 4, 2020

Published online on August 25, 2021

Cite as

Alnassar I, Altinawi M, Rekab MS, Katbeth I, Khasan A, Almokaddam H. Pain assessment following endodontic treatment using two automated systems compared to manual treatment in primary molars. Dent Med Probl. 2021;58(3):305-310. doi:10.17219/dmp/130083

DOI

$10.17219 / \mathrm{dmp} / 130083$

Copyright

○) 2021 by Wroclaw Medical University

This is an article distributed under the terms of the

Creative Commons Attribution 3.0 Unported License (CC BY 3.0)

(https://creativecommons.org/licenses/by/3.0/).

\begin{abstract}
Background. Root canal treatment in primary teeth is quite difficult and time-consuming, especially canal preparation. Pain is the most common negative outcome following root canal treatment, occurring hours or days after treatment. It is an unpleasant experience for both the patient and the dentist.

Objectives. The objective of this study was to assess the severity and duration of pain following the endodontic treatment of primary molars with the use of rotary and reciprocating preparation systems compared to the traditional manual method.

Material and methods. The research sample consisted of 157 asymptomatic primary lower second molars with non-vital pulp that were indicated for root canal treatment. The patients were randomly divided into 3 groups: in the $1^{\text {st }}$ group, the molars $(n=52)$ were prepared using the manual method; in the $2^{\text {nd }}$ group $(n=53)$, a reciprocating automated preparation system (WaveOne ${ }^{\circledR}$ ) was used; and in the $3^{\text {rd }}$ group $(n=52)$, a rotary preparation system (ProTaper Next ${ }^{\circledR}$ ) was used. Pain assessment was carried out after 6, 12, 24, 48, and $72 \mathrm{~h}$, and after 1 week, using a four-face facial pain scale.

Results. The manual method provided a higher pain score through 6,12 and $24 \mathrm{~h}(p<0.05)$ as compared to the 2 automated preparation systems. The intensity of pain did not vary between the 2 machine preparation systems after $6,12,24$, and $48 \mathrm{~h}(p>0.05)$. There were no differences between the 3 methods after $72 \mathrm{~h}$ and after 1 week $(p>0.05)$.

Conclusions. The manual method caused more pain than the other 2 preparation systems, but there was no difference between the 2 automated methods. Automated root canal preparation systems could be used to reduce the intensity of postoperative pain after the endodontic treatment of primary teeth.
\end{abstract}

Keywords: ProTaper Next, rotary system, reciprocating system, WaveOne, deciduous molars 


\section{Introduction}

Root canal treatment in primary teeth is quite difficult and time-consuming, especially canal preparation. Despite the complicated anatomical form of complex molar roots, root canal treatment must be considered an essential option, especially in cases of pulpitis. ${ }^{1}$

Pain with or without edema is the most common adverse effect of root canal treatment. It can occur hours or days after treatment, and is an unpleasant experience for both the patient and the dentist. Debris extruded from the apical foramen during canal preparation can induce an acute inflammatory response, which leads to postoperative pain. ${ }^{2}$

In 2000, Barr et al. described the advantages of using rotary instrumentation techniques for the preparation of primary teeth. ${ }^{3}$ Many studies have concluded that automated systems significantly reduce chairside time and are able to maintain the anatomical form of primary molar roots while reducing the errors that can occur when using the manual system, such as instrument fracture..$^{3,4}$ Nickel-titanium (NiTi) files have been found to be more flexible, allowing easy access to all canals and reducing instrument failure in comparison with K-file hand instrumentation, which increases efficiency in terms of preparation time. ${ }^{4}$

A rotary system (ProTaper Next ${ }^{\circledR}$; Dentsply Sirona, Ballaigues, Switzerland) with a distinctive design, made of M-Wire NiTi alloy to enhance the flexibility and cyclic fatigue resistance of the files was introduced in $2000 .^{5}$

Studies have investigated the use of a reciprocating system (WaveOne ${ }^{\circledR}$; Dentsply Maillefer, Ballaigues, Switzerland) to shape root canals. ${ }^{6}$ Primary reciprocating files use a pecking motion as an alternative to a rotational motion in the preparation of curved canals with a single file. This technique enables preparing canals safely, with better irrigation and less dentin being removed from the inner walls of the root canal. ${ }^{7}$

WaveOne is a system that applies an alternating motion in preparation with a single file of 3 sizes: small (21/06); primary (25/08); and large (40/08) ${ }^{8}$

To our knowledge, few studies have assessed postoperative pain following the endodontic treatment of primary molars with the use of rotational and alternating automated regimens compared to the manual system. ${ }^{9-11}$ Therefore, the purpose of this study was to assess postoperative pain after the canal instrumentation of primary molars with the WaveOne and ProTaper Next preparation systems compared to the traditional manual method.

\section{Material and methods}

The sample size was calculated using G*Power software (https://www.psychologie.hhu.de/arbeitsgruppen/ allgemeine-psychologie-und-arbeitspsychologie/gpower) based on a previous study, ${ }^{9}$ where the study strength was 0.91 with a $5 \%$ level of significance. The sample size required for each group was determined to be 50 patients. Five patients were added to each group in anticipation of withdrawal from the study, giving the total number of 55 patients in each group.

The study was approved by the Ethics Committee of Damascus University, Syria (the approval No. 1438). Informed consent was obtained from each child's parents after a thorough explanation of the study protocol and treatment requirements.

The inclusion criteria were as follows: cooperative children aged 5-8 years; absence of physical or mental disability that would prevent the child from understanding treatment instructions; presence of pulp necrosis caused by carious exposure in primary second molars with at least $2 / 3$ of the root length present, with no signs of fistulae, swelling or pathological tooth mobility; and no evidence of pathology on radiological images (bifurcation lesions, apical lesions or periapical abscesses).

The exclusion criteria were as follows: patients with immune or systemic diseases; patients who took painkillers $12 \mathrm{~h}$ before treatment; and patients who refused to participate in the study.

The patients were distributed randomly into study groups by asking them to select a ball from a dark box that contained 3 balls numbered from 1 to 3 ; the balls determined the patient's study group number.

The treatment was completed in 1 session. It was performed by one dentist according to the following method: - application of local anesthetic (2\% lidocaine with 1:200,000 adrenaline);

- isolation of the tooth with a rubber dam;

- removal of caries followed by opening the pulp chamber with cooling water while making sure the pulp was completely non-vital and that there was no hemorrhage in the canals;

- determination of the canal length with an apex locator so that the final length was $1 \mathrm{~mm}$ shorter than the point 0.0 indicated on the device (the final length was confirmed with an X-ray);

- irrigation of the canal with $5 \mathrm{~mL}$ of $1 \%$ sodium hypochlorite solution after using each file with a syringe and a 29-gauge double sideport NaviTip ${ }^{\text {TM }}$ irrigation needle (Ultradent Products Inc., South Jordan, USA).

The research sample ultimately consisted of 157 asymptomatic primary lower second molars with non-vital pulp. The study groups were prepared in the following order:

- group 1 ( $n=52)$ (manual method): The balanced force technique was used. The mesial canals were instrumented manually with K-files (Dentsply Maillefer) $15 / 02,20 / 02$ and $25 / 02$ used sequentially. The distal canals were instrumented with files $15 / 02,20 / 02$, $25 / 02,30 / 02$, and $35 / 02$, applying irrigation after using each file; 
- group $2(n=53)$ (WaveOne system): All canals were prepared with small file $(21 / 06)$ instrumentation in accordance with the manufacturer's instructions;

- group $3(n=52)$ (ProTaper Next system): The mesial canals were prepared with ProTaper files X1 (17/04) to expand the coronal part of the canal and X2 (25/06) to achieve the full working length. The distal canals were prepared with file $\mathrm{X} 1$ to expand the coronal part, and files X2 and X3 (30/07) to achieve the full working length. Brushing movements were performed gently with an in-and-out motion in accordance with the manufacturer's instructions (rotational speed: $300 \mathrm{rpm}$; torque: $200 \mathrm{gcm}$ ), applying irrigation after using each file.

Each file was used only once and there were no complications associated with any technique.

After that, each canal was washed with $2 \mathrm{~mL}$ of distilled water, dried with paper pins, and then injected with a combination of calcium hydroxide with iodoform (Metapex; Meta Biomed Co. Ltd., Cheongju, South Korea). Finally, the teeth were restored with stainless steel crowns (Kids Crown; Shinhung Co. Ltd., Seoul, South Korea).

After the treatment was completed, the parents were given instructions about how to use the four-face pain scale denoted by numbers: 0 - no pain; 1 - slight pain; 2 - moderate pain; and 3 - severe pain (Fig. 1).

The parents were given a pain relief prescription in case of severe pain (ibuprofen or paracetamol if there was a contraindication to ibuprofen).

The numbers were recorded after communication by telephone with the parents, who did not know the working protocol. They reported to the doctor at the following points in time: $6,12,24,48$, and $72 \mathrm{~h}$, and 1 week after treatment.

\section{Statistical analysis}

The Mann-Whitney and Kruskal-Wallis tests were used to assess the severity and duration of pain, and to study differences between the groups. The IBM SPSS Statistics for Windows software, v. 20.0 (IBM Corp., Armonk, USA) was used for data analysis. The results were considered to be statistically significant at $p \leq 0.05$.

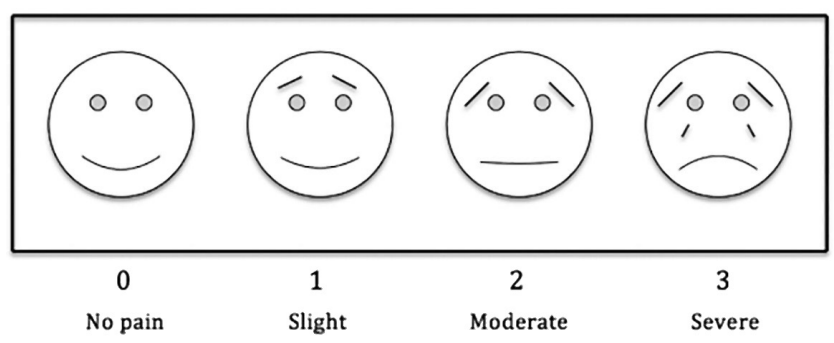

Fig. 1. Pain scale used in the study

\section{Results}

The study began with 165 patients in 3 groups. Eight patients were excluded from the study due to our inability to contact them after the treatment. In the $1^{\text {st }}$ group, the molars $(n=52)$ were prepared using the manual method. In the $2^{\text {nd }}$ group $(n=53)$, a reciprocating automated preparation system (WaveOne) was used. In the $3^{\text {rd }}$ group $(n=52)$, a rotary preparation system (ProTaper Next) was used.

Table 1 details the distribution of patients in the study groups with their gender and average age. Table 2 presents the descriptive pain scores in the 3 study groups. The severity of pain and differences between the 3 groups at the time points $6,12,24,48$, and $72 \mathrm{~h}$, and 1 week after the treatment were recorded (Table 3). Table 4 provides the test results of Mann-Whitney pairwise comparisons at 6,12 and $24 \mathrm{~h}$. No patients manifested severe pain requiring analgesia.

The pain intensity was higher in the $1^{\text {st }}$ group (manual preparation group) as compared to the 2 automated preparation system groups at the time points 6,12 and $24 \mathrm{~h}$ $(p<0.05)$, and $48 \mathrm{~h}(p>0.05)$ after the treatment. There were no differences between the 3 groups at $72 \mathrm{~h}$ and 1 week after the treatment $(p>0.05)$. It was observed that there were no differences between the 2 machine systems at the time points $6,12,24,48$, and $72 \mathrm{~h}$, and 1 week after the treatment $(p>0.05)$.

Table 1. Gender distribution and average age of the patients

\begin{tabular}{|c|c|c|c|}
\multirow{2}{*}{$\begin{array}{l}\text { Patients' } \\
\text { characteristics }\end{array}$} & \multicolumn{3}{|c|}{ Group } \\
\cline { 2 - 4 } & hand files & WaveOne & ProTaper Next \\
\hline $\begin{array}{l}\text { Males } \\
n\end{array}$ & 27 & 29 & 30 \\
$\begin{array}{l}\text { Females } \\
n\end{array}$ & 25 & 24 & 22 \\
$\begin{array}{l}\text { Age [years] } \\
M \pm S D\end{array}$ & $6.80 \pm 0.50$ & $6.95 \pm 0.90$ & $7.84 \pm 0.64$ \\
\hline
\end{tabular}

$M$ - mean; SD - standard deviation.

Table 2. Descriptive pain scores in the 3 study groups

\begin{tabular}{|l|c|c|c|c|c|c|c|c|c|c|}
\multirow{2}{*}{$\begin{array}{c}\text { Assessment } \\
\text { time }\end{array}$} & \multicolumn{3}{|c|}{$\begin{array}{c}\text { Hand files } \\
n=52\end{array}$} & \multicolumn{3}{c|}{$\begin{array}{c}\text { WaveOne } \\
n=53\end{array}$} & \multicolumn{3}{c|}{$\begin{array}{c}\text { ProTaper Next } \\
n=52\end{array}$} \\
\cline { 2 - 11 } & $M$ & Me & $S D$ & $M$ & $M e$ & $S D$ & $M$ & $M e$ & $S D$ \\
\hline $6 h$ & 1.15 & 1.00 & 0.78 & 0.72 & 1.00 & 0.72 & 0.69 & 1.00 & 0.76 \\
$12 \mathrm{~h}$ & 0.85 & 1.00 & 0.83 & 0.64 & 1.00 & 0.71 & 0.56 & 0.00 & 0.73 \\
$24 \mathrm{~h}$ & 0.60 & 0.00 & 0.75 & 0.42 & 0.00 & 0.66 & 0.40 & 0.00 & 0.66 \\
$48 \mathrm{~h}$ & 0.48 & 0.00 & 0.75 & 0.30 & 0.00 & 0.57 & 0.29 & 0.00 & 0.61 \\
$72 \mathrm{~h}$ & 0.12 & 0.00 & 0.32 & 0.08 & 0.00 & 0.27 & 0.08 & 0.00 & 0.27 \\
\hline
\end{tabular}

Me-median 
Table 3. Distribution of the patients from the 3 study groups in terms of pain severity and duration (Kruskal-Wallis test)

\begin{tabular}{|c|c|c|c|c|c|}
\hline Assessment time & Pain & $\begin{array}{l}\text { Hand files } \\
(n=52)\end{array}$ & $\begin{array}{l}\text { WaveOne } \\
(n=53)\end{array}$ & $\begin{array}{l}\text { ProTaper Next } \\
\quad(n=52)\end{array}$ & $p$-value \\
\hline \multirow{4}{*}{$6 \mathrm{~h}$} & none & $12(23.1)$ & $23(43.4)$ & $25(48.1)$ & \multirow{4}{*}{$<0.05^{*}$} \\
\hline & slight & $20(38.5)$ & $22(41.5)$ & $18(34.6)$ & \\
\hline & moderate & $20(38.5)$ & $8(15.1)$ & $9(17.3)$ & \\
\hline & severe & $0(0)$ & $0(0)$ & $0(0)$ & \\
\hline \multirow{4}{*}{$12 \mathrm{~h}$} & none & $22(42.3)$ & $26(49.1)$ & $30(37.7)$ & \multirow{4}{*}{$<0.05^{*}$} \\
\hline & slight & $16(30.8)$ & $20(37.7)$ & 15 (28.8) & \\
\hline & moderate & $14(26.9)$ & $7(13.2)$ & $7(13.5)$ & \\
\hline & severe & $0(0)$ & $0(0)$ & $0(0)$ & \\
\hline \multirow{4}{*}{$24 \mathrm{~h}$} & none & $29(55.8)$ & $36(67.9)$ & $36(69.2)$ & \multirow{4}{*}{$>0.05$} \\
\hline & slight & $15(28.8)$ & $12(22.6)$ & $11(21.2)$ & \\
\hline & moderate & $8(15.4)$ & $5(9.4)$ & $5(9.6)$ & \\
\hline & severe & $0(0)$ & $0(0)$ & $0(0)$ & \\
\hline \multirow{4}{*}{$48 \mathrm{~h}$} & none & $35(67.3)$ & $40(75.5)$ & $41(78.8)$ & \multirow{4}{*}{$>0.05$} \\
\hline & slight & $9(17.3)$ & $10(8.9)$ & $7(13.5)$ & \\
\hline & moderate & $8(15.4)$ & $3(5.7)$ & $4(7.7)$ & \\
\hline & severe & $0(0)$ & $0(0)$ & $0(0)$ & \\
\hline \multirow{4}{*}{$72 \mathrm{~h}$} & none & $46(88.5)$ & $49(92.5)$ & $48(92.3)$ & \multirow{4}{*}{$>0.05$} \\
\hline & slight & $6(11.5)$ & $4(7.5)$ & $4(7.7)$ & \\
\hline & moderate & $0(0)$ & $0(0)$ & $0(0)$ & \\
\hline & severe & $0(0)$ & $0(0)$ & $0(0)$ & \\
\hline \multirow{4}{*}{1 week } & none & $0(0)$ & $0(0)$ & $0(0)$ & \multirow{4}{*}{ - } \\
\hline & slight & $0(0)$ & $0(0)$ & $0(0)$ & \\
\hline & moderate & $0(0)$ & $0(0)$ & $0(0)$ & \\
\hline & severe & $0(0)$ & $0(0)$ & $0(0)$ & \\
\hline
\end{tabular}

* statistically significant.

Data presented as number (percentage) (n (\%)).

Table 4. Pairwise comparisons between the 3 study groups as a post-hoc test at 6,12 and $24 \mathrm{~h}$ (Mann-Whitney test)

\begin{tabular}{|ll|}
\multicolumn{1}{|c|}{ Group pairs } & $p$-value \\
\hline Hand files vs WaveOne & $<0.05^{*}$ \\
Hand files vs ProTaper Next & $<0.05^{*}$ \\
WaveOne vs ProTaper Next & $>0.05$ \\
\hline
\end{tabular}

${ }^{*}$ statistically significant.

\section{Discussion}

Pain associated with root canal treatment is a major source of fear and a very important concern for patients. Studies have found a postoperative pain rate of $1.9-48.9 \%$, which causes anxiety in patients. ${ }^{12,13}$ Therefore, finding the best instrumentation techniques that cause the least amount of pain after root canal treatment is an essential objective of clinical practice. To our knowledge, few studies have compared postoperative pain following the endodontic treatment of primary molars with the use of rotational and alternating automated regimens compared to the conventional manual system. ${ }^{9-11}$

Thus, the purpose of this study was to assess the intensity of pain following the root canal treatment of primary molars with 2 automated (rotary and reciprocating) preparation systems compared to the conventional manual system at the time points $6,12,24,48$, and $72 \mathrm{~h}$, and 1 week after the treatment. The study involved asymptomatic primary second molars with non-vital pulp to avoid bias resulting from the tooth type and the pulp 
condition. Sodium hypochlorite solution (1\%) was used as an irrigation solution in accordance with the recommendations of the American Society of Pediatric Dentistry, as it is not recommended to use a high concentration of sodium hypochlorite solution in children. ${ }^{14}$

An apex locator was used to determine the working length. Many studies have confirmed the ability of the apex locator to determine the working length, even in the presence of resorption. ${ }^{15,16}$ The facial pain scale implemented in many studies was used to assess pain severity in this study. ${ }^{9,10,17}$

During the mechanical and chemical preparation of root canals, debris (including dentinal particles, the irrigation solution, necrotic pulp tissues, and microorganisms) is propelled into the apical foramen, which may lead to an inflammatory response in the area around the apex and postoperative pain; it may also cause harm to the permanent tooth bud. ${ }^{2}$

The results of this study determined that there was posttreatment pain in all 3 groups, but pain intensity was higher in the manual preparation group as compared to the 2 automatic preparation systems at 6,12 and $24 \mathrm{~h}(p<0.05)$, which is consistent with a study by Topçuoğlu et al. ${ }^{9}$ Conversely, there were no differences in pain perception between the 3 groups at $72 \mathrm{~h}$ and 1 week post-treatment $(p<0.05)$, which is consistent with the results of studies conducted by Topçuoğlu et al. ${ }^{9}$ and Nair et al. ${ }^{10}$ However, it should be noted that their comparison was limited to only 2 preparation systems (manual and rotary).

Jeevanandan et al. concluded that there was more postoperative pain due to NiTi K-flex files used in a reciprocating motion followed by manual NiTi K-flex files and Kedo-S pediatric rotary files, ${ }^{11}$ which does not match our findings. This could be due to differences in the tooth types treated and the systems used for preparation.

Our results are consistent with a systematic review by Manchanda et al., who found that there was less posttreatment pain while using an automated preparation system at the time points $6 \mathrm{~h}(p<0.05)$ and $48 \mathrm{~h}(p>0.05)$ when compared with a manual system. ${ }^{18}$ Also, no difference in pain intensity between manual and rotary systems at the $72 \mathrm{~h}$ point was found. ${ }^{18}$ Conversely, our study concluded that the use of the manual preparation system led to an increase in pain intensity 12 and $24 \mathrm{~h}$ after the treatment $(p<0.05)$, whereas Manchanda et al. stated that the levels of pain were similar for the 2 systems (manual and automated). ${ }^{18}$

It is speculated that a manual system propels a greater quantity of debris toward the region around the apex, which translates into greater pain as compared to the 2 automated preparation systems (rotary and reciprocating). This is consistent with the results of a laboratory study by Alnassar et al. ${ }^{19}$

Many factors could affect the results of the present study, e.g., the preparation technique, the direction of preparation or the characteristics of the preparation tools used. For example, the files of the automatic preparation system ProTaper Next have a distinctive design - an offset center of mass and rotation. The files of this system are based on the crown-down technique, which relies on early coronal expansion. This pushes the preparation residue further into the coronal direction of the canal and reduces thrust in the apical direction. ${ }^{20,21}$ Conversely, the WaveOne system files have a convex, triangular crosssection, with the tip portion having a modified convex, triangular cross-section. ${ }^{6}$ The WaveOne system is based on an alternating movement in preparation, which is a type of balanced force that provides control over the movement of the residue, reducing its thrust in the apical direction. ${ }^{22}$ Manual files, on the other hand, tend to apply a pushing movement acting as a piston in the apical third of the canal, which propels the residue further, and thereby causes more pain. ${ }^{23}$

\section{Conclusions}

The manual method caused more pain than the other 2 preparation systems, but there was no difference in terms of pain caused between the 2 automated methods. Automated root canal preparation systems could be used to reduce the intensity of postoperative pain in the endodontic treatment of primary teeth.

\section{ORCID iDs}

Ibrahim Alnassar (D) https://orcid.org/0000-0002-8197-9171 Mohamed Altinawi (D) https://orcid.org/0000-0002-5637-7320 Mohammad Salem Rekab (1) https://orcid.org/0000-0002-5377-8225 Imad Katbeh (D) https://orcid.org/0000-0002-4591-7694

Alexander Khasan (D) https://orcid.org/0000-0001-5671-2240

Hayan Almokaddam (1) https://orcid.org/0000-0001-9527-129X

\section{References}

1. Pinheiro SL, Araujo G, Bincelli I, Cunha R, Bueno C. Evaluation of cleaning capacity and instrumentation time of manual, hybrid and rotary instrumentation techniques in primary molars. Int Endod J. 2012;45(4):379-385. doi:10.1111/j.1365-2591.2011.01987.x

2. Adl A, Sahebi S, Moazami F, Niknam M. Comparison of apical debris extrusion using a conventional and two rotary techniques. Iran Endod J. 2009;4(4):135-138.

3. Barr ES, Kleier DJ, Barr NV. Use of nickel-titanium rotary files for root canal preparation in primary teeth. Pediatr Dent. 2000;22(1):77-78.

4. Nagaratna PJ, Shashikiran ND, Subbareddy VV. In vitro comparison of NiTi rotary instruments and stainless steel hand instruments in root canal preparations of primary and permanent molar. JIndian Soc Pedod Prev Dent. 2006;24(4):186-191. doi:10.4103/0970-4388.28075

5. Elnaghy AM, Al-Dharrab AA, Abbas HM, Elsaka SE. Evaluation of root canal transportation, centering ratio, and remaining dentin thickness of TRUShape and ProTaper Next systems in curved root canals using micro-computed tomography. Quintessence Int. 2017;48(1):27-32. doi:10.3290/j.qi.a36895

6. Berutti E, Chiandussi G, Paolino DS, et al. Canal shaping with WaveOne Primary reciprocating files and ProTaper system: A comparative study. J Endod. 2012;38(4):505-509. doi:10.1016/j.joen.2011.12.040

7. Metzger Z, Teperovich E, Zary R, Cohen R, Hof R. The self-adjusting file (SAF). Part 1: Respecting the root canal anatomy - a new concept of endodontic files and its implementation. J Endod. 2010;36(4):679-690. doi:10.1016/j.joen.2009.12.036 
8. Plotino G, Grande NM, Testarelli L, Gambarini G. Cyclic fatigue of Reciproc and WaveOne reciprocating instruments. Int Endod J. 2012;45(7):614-618. doi:10.1111/j.1365-2591.2012.02015.x

9. Topçuoğlu G, Topçuoğlu HS, Delikan E, Aydınbelge M, Dogan S. Postoperative pain after root canal preparation with hand and rotary files in primary molar teeth. Pediatr Dent. 2017;39(3):192-196.

10. Nair M, Jeevanandan G, Ravindran V, Subramanian EMG. Comparative evaluation of post-operative pain after pulpectomy with k-files, kedo-s files and mtwo files in deciduous molars - a randomized clinical trial. Braz Dent Sci. 2018;21(4):411-417. doi:10.14295/bds.2018.v21i4.1617

11. Jeevanandan G, Ravindran V, Subramanian EMG, Kumar AS. Postoperative pain with hand, reciprocating, and rotary instrumentation techniques after root canal preparation in primary molars: A randomized clinical trial. Int J Clin Pediatr Dent.2020;13(1):21-26. doi:10.5005/jp-journals-10005-1709

12. Ng YL, Glennon JP, Setchell DJ, Gulabivala K. Prevalence of and factors affecting post-obturation pain in patients undergoing root canal treatment. Int Endod J. 2004;37(6):381-391. doi:10.1111/j.1365-2591.2004.00820.x

13. Pak JG, White SN. Pain prevalence and severity before, during, and after root canal treatment: A systematic review. J Endod. 2011;37(4):429-438. doi:10.1016/j.joen.2010.12.016

14. American Academy of Pediatric Dentistry Clinical Affairs Committee - Pulp Therapy Subcommittee. Guideline on pulp therapy for primary and immature permanent teeth. Pediatr Dent. 2016;38(6):280-288.

15. Kayabasi M, Oznurhan F. Evaluation of the accuracy of electronic apex locators, cone-beam computed tomography, and radiovisiography in primary teeth: An in vitro study. Microsc Res Tech. 2020;83(11):1330-1335. doi:10.1002/jemt.23524

16. Andrade de Alencar N, D'Avila Oriano M, Bolan M, Cardoso M. Is there any difference in length measurement methods for pulpectomies in primary teeth? - A double-blind, controlled clinical trial. Int J Paediatr Dent. 2019;29(6):712-719. doi:/10.1111/ipd.12567

17. Tuncer AK, Gerek M. Effect of working length measurement by electronic apex locator or digital radiography on postoperative pain: A randomized clinical trial. J Endod. 2014;40(1):38-41. doi:10.1016/j.joen.2013.08.004

18. Manchanda S, Sardana D, Yiu CKY. A systematic review and metaanalysis of randomized clinical trials comparing rotary canal instrumentation techniques with manual instrumentation techniques in primary teeth. Int Endod J. 2020;53(3):333-353. doi:10.1111/iej.13233

19. Alnassar I, Alsafadi AS, Kouchaji C. Assessment of the apically extruded debris between a rotary system, a reciprocating system and hand files during the root canal instrumentation of the deciduous molars. Dent Med Probl. 2019;56(1):53-57. doi:10.17219/dmp/99655

20. Ruddle CJ, Machtou P, West JD. The shaping movement: Fifthgeneration technology. Dent Today. 2013;32(4):94,96-99.

21. Aksel H, Eren SK, Çakar A, Serper A, Özkuyumcu C, Azim AA. Effect of instrumentation techniques and preparation taper on apical extrusion of bacteria. J Endod. 2017;43(6):1008-1010. doi:10.1016/j.joen.2017.01.014

22. Haridas $K$, Hariharan $M$, Singh $P$, Varughese $A$, Ravi $A B$, Varma KR. Effect of instrumentation techniques and kinematics on apical extrusion of debris: An in vitro study. $J$ Contemp Dent Pract. 2019;20(9):1067-1070.

23. Topçuoğlu HS, Demirbuga S, Topçuoğlu G. Evaluation of apically extruded debris during the removal of canal filling material using three different $\mathrm{Ni}$-Ti systems and hand files in teeth with simulated apical root resorption. Int Endod J. 2020;53(3):403-409. doi:10.1111/iej.13234 